ARTICLE

\title{
Morphological bases of phytoplankton energy management and physiological responses unveiled by 3D subcellular imaging
}

\author{
Clarisse Uwizeye (10 ${ }^{1}$, Johan Decelle ${ }^{1 凶}$, Pierre-Henri Jouneau (10) ${ }^{2}$, Serena Flori ${ }^{1,3}$, Benoit Gallet (1) ${ }^{4}$, \\ Jean-Baptiste Keck (10) ${ }^{5}$, Davide Dal Bo ${ }^{1}$, Christine Moriscot ${ }^{4,6}$, Claire Seydoux ${ }^{1}$, Fabien Chevalier ${ }^{1}$, \\ Nicole L. Schieber (10 7, Rachel Templin7, Guillaume Allorent ${ }^{1}$, Florence Courtois', Gilles Curien', \\ Yannick Schwab ${ }^{7,8}$, Guy Schoehn (1) ${ }^{4}$, Samuel C. Zeeman ${ }^{9}$, Denis Falconet (D) ${ }^{1 凶}$ \& Giovanni Finazzi (i) ${ }^{1 凶}$
}

Eukaryotic phytoplankton have a small global biomass but play major roles in primary production and climate. Despite improved understanding of phytoplankton diversity and evolution, we largely ignore the cellular bases of their environmental plasticity. By comparative 3D morphometric analysis across seven distant phytoplankton taxa, we observe constant volume occupancy by the main organelles and preserved volumetric ratios between plastids and mitochondria. We hypothesise that phytoplankton subcellular topology is modulated by energy-management constraints. Consistent with this, shifting the diatom Phaeodactylum from low to high light enhances photosynthesis and respiration, increases cell-volume occupancy by mitochondria and the plastid $\mathrm{CO}_{2}$-fixing pyrenoid, and boosts plastidmitochondria contacts. Changes in organelle architectures and interactions also accompany Nannochloropsis acclimation to different trophic lifestyles, along with respiratory and photosynthetic responses. By revealing evolutionarily-conserved topologies of energy-managing organelles, and their role in phytoplankton acclimation, this work deciphers phytoplankton responses at subcellular scales.

\footnotetext{
${ }^{1}$ Univ. Grenoble Alpes, CNRS, CEA, INRAe, IRIG-LPCV, Grenoble, France. ${ }^{2}$ Univ. Grenoble Alpes, CEA, IRIG-MEM, Grenoble, France. ${ }^{3}$ The Marine Biological Association, The Laboratory, Citadel Hill Plymouth, Devon, UK. ${ }^{4}$ Univ. Grenoble Alpes, CNRS, CEA, IRIG-IBS, Grenoble, France. ${ }^{5}$ Univ. Grenoble Alpes, Laboratoire Jean Kuntzmann, Grenoble, France. ${ }^{6}$ Univ. Grenoble Alpes, CNRS, CEA, EMBL, Integrated Structural Biology Grenoble (ISBG), Grenoble, France. ${ }^{7}$ Cell Biology and Biophysics Unit, European Molecular Biology Laboratory, Heidelberg, Germany. ${ }^{8}$ Electron Microscopy Core Facility, European Molecular Biology Laboratory, Heidelberg, Germany. ${ }^{9}$ Institute of Molecular Plant Biology, Department of Biology, ETH Zurich, Zurich, Switzerland. 凶email: johan.decelle@univ-grenoble-alpes.fr; denis.falconet@cea.fr; giovanni.finazzi@cea.fr
} 
P hytoplankton play a critical role in supporting life on Earth. By converting $\mathrm{CO}_{2}$, sunlight and nutrients into biomass and oxygen, unicellular phototrophs are responsible for about $50 \%$ of primary productivity ${ }^{1}$. They also contribute to food webs and to the biological $\mathrm{CO}_{2}$ pump in the oceans. Phytoplankton members are ubiquitous in marine and freshwater ecosystems and include prokaryotes and eukaryotes, the latter having acquired photosynthesis capacity up to 1.5 billion years ago through endosymbiotic events ${ }^{2}$. Eukaryotic phytoplankton encompasses a great diversity of lineages (e.g. diatoms, dinoflagellates, haptophytes, chlorophytes, rhodophytes) with different morphologies and sizes (from 0.8 to a few tens of microns) ${ }^{3}$. Although our knowledge on phytoplankton biodiversity and ecological relevance in aquatic ecosystems has greatly improved in the recent years (e.g. ref. ${ }^{4}$ ), the cellular bases of ecological responses of these unicellular organisms remain undetermined. Moreover, we do not know how flexible the phytoplankton cellular and organellar architecture is when facing environmental changes. This is a critical aspect, as recent works have proposed that phytoplankton physiological responses may rely on specific subcellular features ${ }^{5,6}$.

So far, phytoplankton morphological features have been mainly visualized by light microscopy and two-dimensional (2D) electron microscopy studies ${ }^{7-11}$, often associated with the assessment of photosynthetic activity ${ }^{10,12}$. High-throughput confocal fluorescence three-dimensional (3D) imaging has been developed to scan, classify and quantify phytoplankton cells collected in different oceanic regions ${ }^{13}$. However, optical microscopy studies have insufficient resolution to reveal cellular ultrastructure, and 2D electron microscopy by definition cannot provide a comprehensive volumetric description of phytoplankton cells and their organelles.

Thanks to the recent development of $3 \mathrm{D}$ electron microscopy methods $^{14-16}, 3 \mathrm{D}$ reconstructions have been obtained to analyse plant cell division ${ }^{17}$, chloroplast biogenesis ${ }^{18}$, with emphasis on thylakoids organization ${ }^{19-23}$ and algal cell structures ${ }^{24-28}$. Serial block-face electron microscopy (SBEM) has been used to analyse plant subcellular architectures ${ }^{29-31}$. Ion-beam milling was used to prepare thin lamella for imaging by cryo-EM ${ }^{32}$, revealing the native architecture of the Chlamydomonas reinhardtii chloroplast ${ }^{6,33,34}$. Focused ion beam scanning electron microscopy (FIB-SEM) has been used to reveal the $3 \mathrm{D}$ structure of photosynthetic cells with enough resolution $(4-10 \mathrm{~nm})$ to investigate their subcellular architecture. This technique has been applied to chemically fixed samples in rice 35,36 , Chlamydomonas 37,38 , in the diatom Phaeodactylum tricornutum ${ }^{39,40}$, and to cryo-fixed and freeze substituted Phaeocystis cordata cells ${ }^{41}$. Cryo-FIB-SEM of highpressure frozen marine algae such as coccolithophores ${ }^{42}$ and dinoflagellates ${ }^{43,44}$ has also been used to study biomineralization pathways. However, we still miss comparative studies to reveal evolutionarily conserved topologies in eukaryotic phytoplankton and to highlight possible links between acclimation responses and changes in subcellular architectures.

Here, we applied a FIB-SEM-based workflow to seven monoclonal cultures of different eukaryotic microalgae representing major oceanic phytoplankton lineages and/or model-laboratory microalgae. We generate $3 \mathrm{D}$ reconstructions, suitable for quantitative morphometric analysis (surfaces and volumes) of organelles and subcellular structures. Comparative analysis of the different lineages reveals preserved structural characteristics between the different species: conserved cell-volume occupancy by the different organelles and constant volumetric ratios in energy-producing organelles (plastids, mitochondria). These relationships between subcellular compartments related to energy management may represent evolutionarily conserved features responsible for specific physiological responses in phytoplankton. Consistent with this idea, physiological responses of microalgae acclimated to either different light regimes or trophic lifestyles are accompanied by commensurate modifications in the structural features of plastids and mitochondria, as well as in their interactions.

\section{Results and discussion}

Cellular architectures of phytoplankton. We reconstructed the 3D cellular architecture of different eukaryotic phytoplankton representatives of ubiquitous taxa and laboratory model organisms: Mammiellophyceae (Micromonas RCC 827), Prymnesiophyceae (Emiliania RCC 909), Pelagophyceae (Pelagomonas RCC 100), Dinophyceae (Symbiodinium RCC 4014 clade A), Cyanidiophyceae (Galdieria SAG 21.92), Bacillariophyceae (Phaeodactylum Pt1 8.6), and Eustigmatophyceae (Nannochloropsis CCMP 526) (Supplementary Table 1). Prior to FIB-SEM imaging, culture aliquots were tested for photosynthetic capacity (Supplementary Table 1) to verify their physiological status. Cells were cryo-fixed using high-pressure freezing (to maximize preservation of native structures) followed by slow freeze substitution and resin embedding. FIB-SEM datasets were processed to 3D models using open-access software (see Supplementary Fig. 1 and methods for details). This imaging approach allows a wide range of cell volumes to be quantified, from ca. $2 \mu \mathrm{m}^{3}$ in the mamiellophyceae Micromonas, to more than $200 \mu \mathrm{m}^{3}$ in the dinoflagellate Symbiodinium.

We observed both external features of microalgae (e.g. the raphe in Phaeodactylum, the flagellum in Micromonas, the coccosphere in Emiliania, Fig. 1), and the main organelles (Fig. 2: nucleus-blue, plastid-green and mitochondria-red). Other cellular features were observed (grey): storage bodies in Emiliania $^{42,45}$, carbon-rich structures in Pelagomonas ${ }^{46}$, large oil bodies in Nannochloropsis ${ }^{47}$, starch sheaths surrounding the pyrenoids in Micromonas ${ }^{48}$ and Symbiodinium, and vacuoles of different sizes in Phaeodactylum ${ }^{49}$, Galdieria and Micromonas ${ }^{48}$.

Different shapes were observed for the main organelles. Plastids were cup-shaped in Galdieria, Pelagomonas, Emiliania, lobed in Symbiodinium, globular in Micromonas and Nannochloropsis and elongated in Phaeodactylum (Fig. 2b and Fig. 3a). When distinguishable, photosynthetic membranes (thylakoids) were organized in layers of a few stacks, but lacked the clear subdivision into stacked grana and unstacked stromal lamellae observed in vascular plants ${ }^{50}$. The nuclei were spherical/oval in shape and were closely associated with the plastids via the fourth envelope membranes in secondary plastids (i.e. Phaeodacty$\left.l u m^{40}\right)$. Mitochondria were characterized by more variable shapes not only between species but also within cells of the same species (e.g. Supplementary Fig. 2 in the case of Emiliania). This diversity probably reflects the dynamic nature of these organelles, which frequently change their shape, undergo dislocations, fusion and fission in eukaryotes ${ }^{51}$.

Quantitative analysis indicates that plastids always occupied the largest fraction (15-40\%) of the cell (Fig. 2c, Supplementary Data 1) in line with recent estimates in vascular plants ${ }^{29,35}$, followed by the nucleus (5-15\%) and the mitochondria $(2.5-5 \%)$. Altogether, these three organelle types (nuclei, plastids and mitochondria) filled a relatively constant fraction (40-55\%) of the total cell volume, despite significant differences in the cell volumes of the different phytoplankton taxa (Symbiodinium e.g. is around 100 times larger than Micromonas). Networks of internal vesicles, the Golgi apparatus, ER, vacuoles and storage compartments (e.g. lipid droplets, starch granules, nutrient storage, etc) and the cytosol occupied the other half with a larger variability in terms of their relative volume occupancy. We interpret this conservation of the organelle volumes and the variability of the other compartments as the signature of evolutionary constraints that preserve essential cellular functions (gene expression, energy production and consumption, 


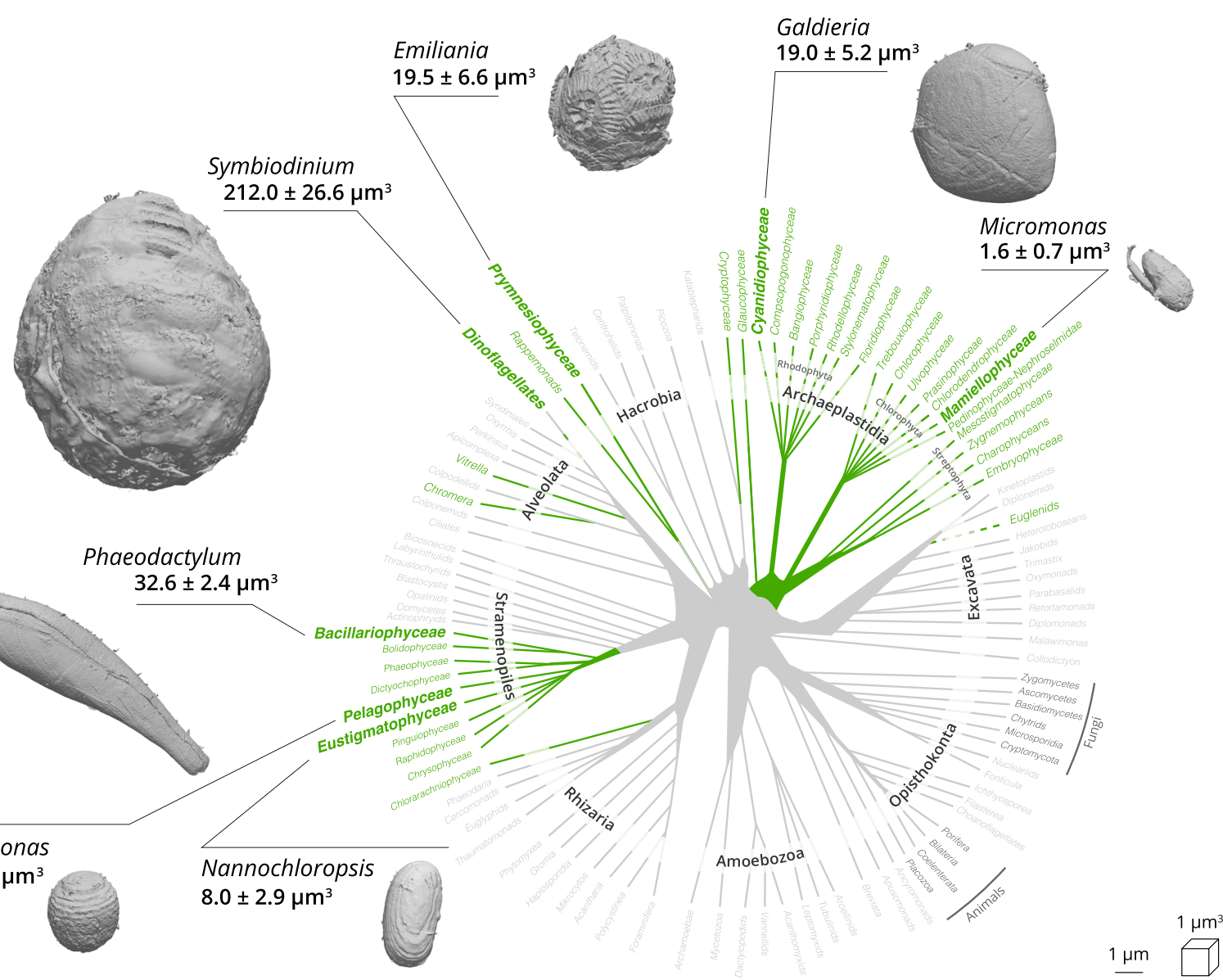

Fig. 1 Cellular volume and external features of selected phytoplankton cells revealed by FIB-SEM imaging. Green branches of the phylogenetic tree of eukaryotes represent photosynthetic lineages (adapted from ref. ${ }^{91}$ ). A 3D scan view of cell morphology of selected phytoplankton members (Mammiellophyceae (Micromonas RCC 827), Prymnesiophyceae (Emiliania RCC 909), Bacillariophyceae (Phaeodactylum Pt1 8.6), Pelagophyceae (Pelagomonas RCC 100), Dinophyceae (Symbiodinium RCC 4014 clade A), Cyanidiophyceae (Galdieria SAG21.92) and Eustigmatophyceae (Nannochloropsis CCMP526) is shown with a linear scale bar of $1 \mu \mathrm{m}$ and a voxel scale of $1 \mu \mathrm{m}^{3}$. Specific cellular features (cell walls, the flagellum in Micromonas, the raphe in Phaeodactylum, the coccosphere in Emiliania) are visible. For every species, three cells were reconstructed and morphometrically analysed. Data represent cell volumes \pm s.d. for every species.

compartmentation of metabolic pathways), while leaving metabolic flexibility to allow the storage of assimilated nutrients, particularly carbon and subcellular trafficking. The only exception was Nannochloropsis, where the large accumulation of oil bodies possibly reduced the cell volume available to the main organelles (22.4 $\pm 4.5 \%$, Fig. 2 , see also below).

Thanks to the possibility to perform quantitative surface and volumetric estimates, we sought relationships between the three above mentioned organelles (Fig. 3) in the different taxa, to identify possible evolutionarily-preserved morphological characteristics. This analysis was initially biased by the presence of Symbiodinium (Supplementary Fig. 3). These dinoflagellate cells, being much larger than the others, led to the clustering of data into two groups (Symbiodinium cells on one side, all the other cells on the other side), preventing the observation of correlation between the other cells.

Excluding Symbiodinium from the analysis removed this bias and unveiled the existence of a tight correlation between plastids and mitochondria in terms of volume (the coefficient of determination $R^{2}$, being 0.95 , Fig. $3 \mathrm{~b}$ ) and surface area ratios $\left(R^{2}=0.85\right.$, Fig. 3c).

No significant correlation was found between the volume/surface ratio of the nucleus and the mitochondria or plastid $\left(R^{2} \leq 0.5\right)$. Plastid-mitochondria relationships are of primary importance in diatoms 5,52 , where interactions between the two organelles are relevant for carbon assimilation. Based on the findings above, it is possible that this organelle-organelle relationship also exists in other microalgal species.

Plastid-mitochondria interactions may rely on physical interactions between the two organelles ${ }^{39,53}$. We tested this possibility by quantifying possible contact points between plastids and mitochondria in the different species analysed above (Fig. 4). Recent work based on cryo-electron tomography of cyanobacterial cells has revealed specific contact sites between thylakoids and the plasma membrane with a $\sim 3 \mathrm{~nm}$ intermembrane space $\mathrm{e}^{54}$. Using the same technique, ER-plasma membrane, ER-mitochondria, and nucleus-vacuole contact sites were measured in eukaryotic cells with intermembrane distances of $\sim 20 \mathrm{~nm}, \sim 10 \mathrm{~nm}$, and $\sim 15 \mathrm{~nm}$, respectively ${ }^{55,56}$. Based on these results, we chose a distance value of $\leq 30 \mathrm{~nm}$ to calculate surface areas of contact between plastids and mitochondria. We could identify contacts in Phaeodactylum ( $7.1 \pm 1.1 \%$ of the plastid surface being involved in contacts with mitochondria, Fig. 4a), in agreement with the previous suggestions $^{5}$. Conversely, contacts turned out to be almost negligible in all the other organisms, ranging from $0.1 \pm 0.1$ in Pelagomonas to $1.8 \pm 0.8 \%$ of the plastid surface in Emiliania.

Other distance criteria have been proposed to operationally track contact points between organelles in light microscopy ${ }^{57}$. 
(a)

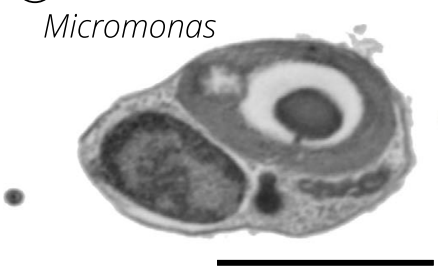

Pelagomonas

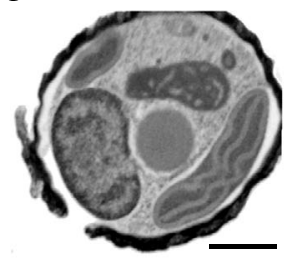

Nannochloropsis

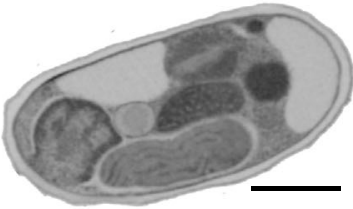

Galdieria

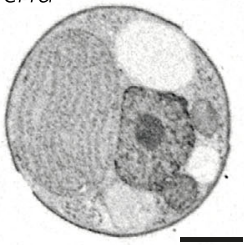

Emiliania

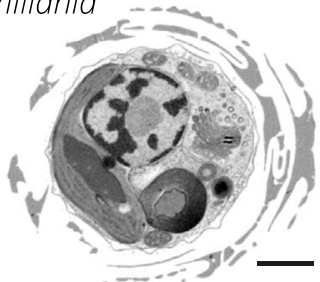

Phaeodactylum

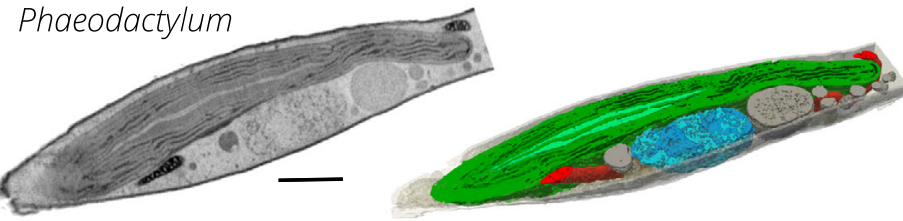

Symbiodinium

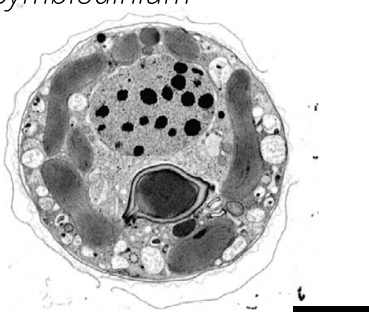

(b)
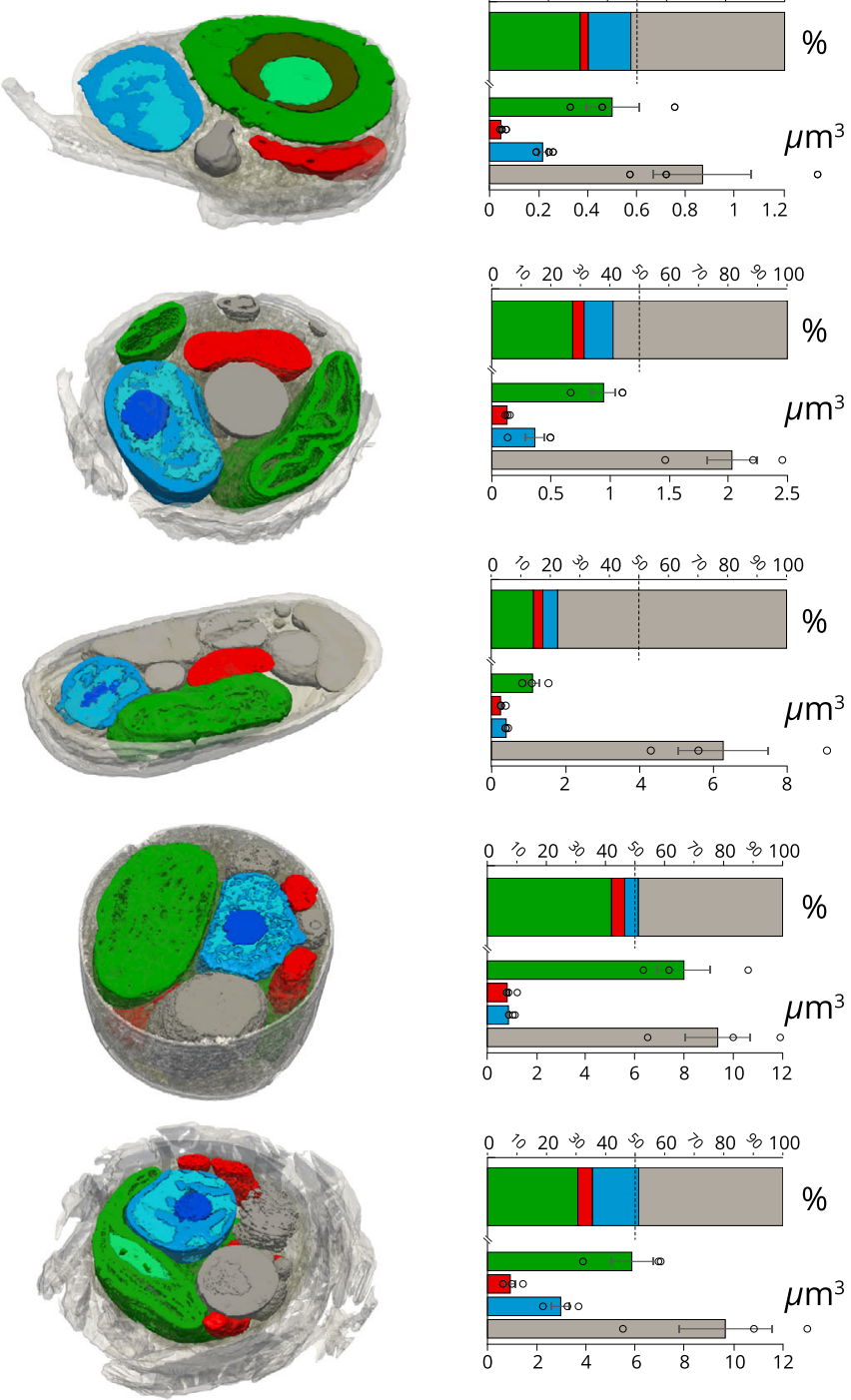

0 ? 20 งo 40 so $60 \div 80$ ? 100

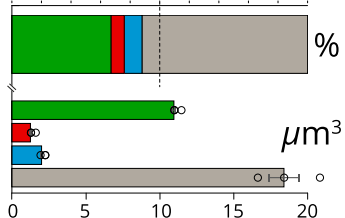

$0 \geqslant 203_{0} 40$ so $60 \div 809_{0} 100$

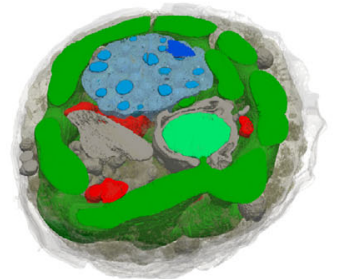

Plastid Mitochondria

(C)
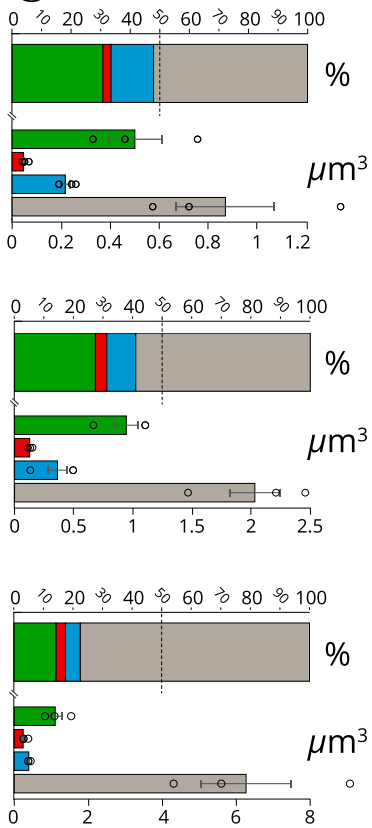

$0 \div 203_{0} 40 s_{0} 60 \div 80 \% 100$

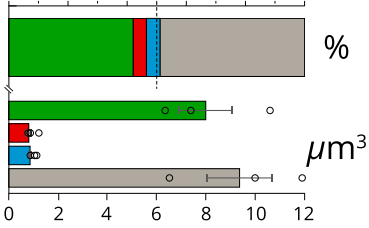

\section{3}

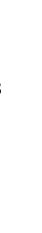

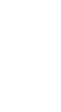


(a)

$\stackrel{i}{i}$

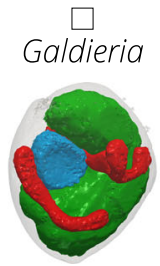

$\square$

$\bigcirc$
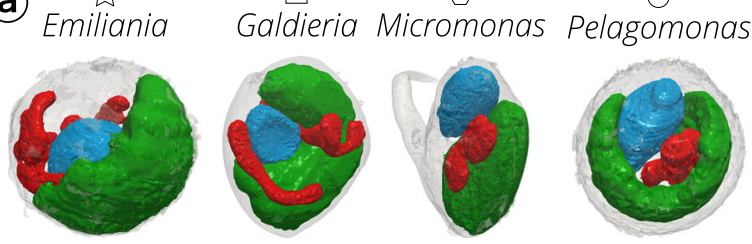

$\triangle$

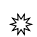

(b)

\section{VOLUME}
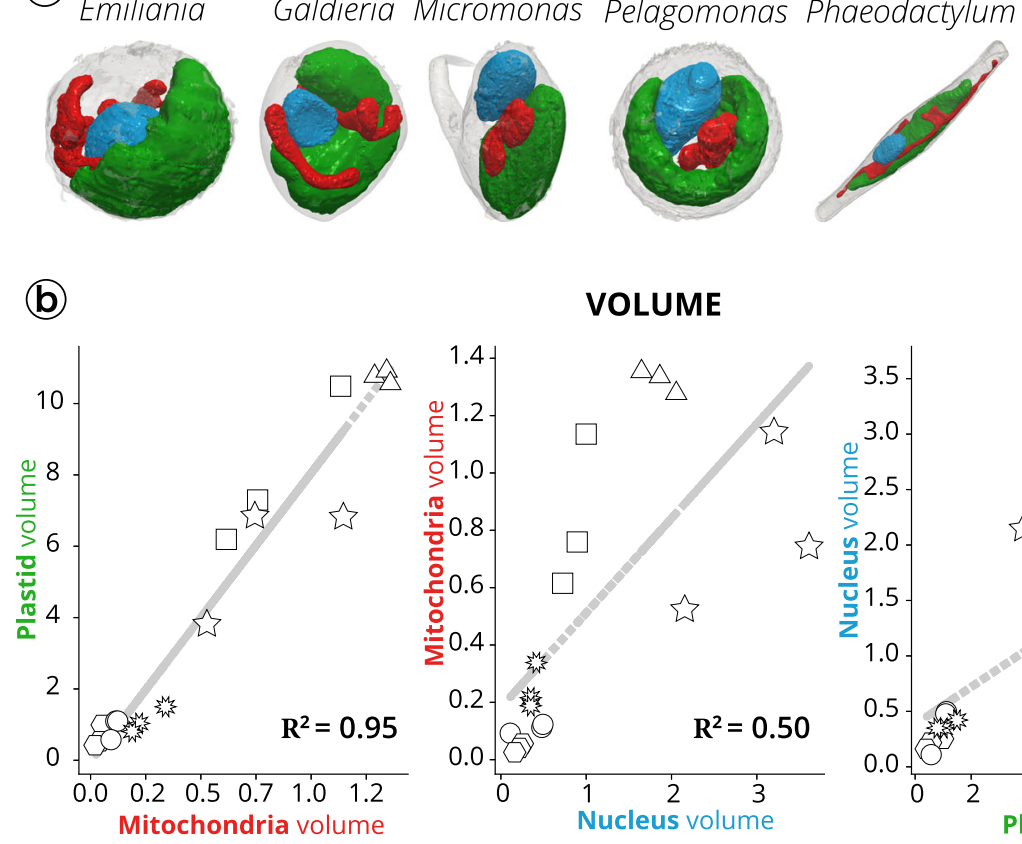

ochloropsis

(c)
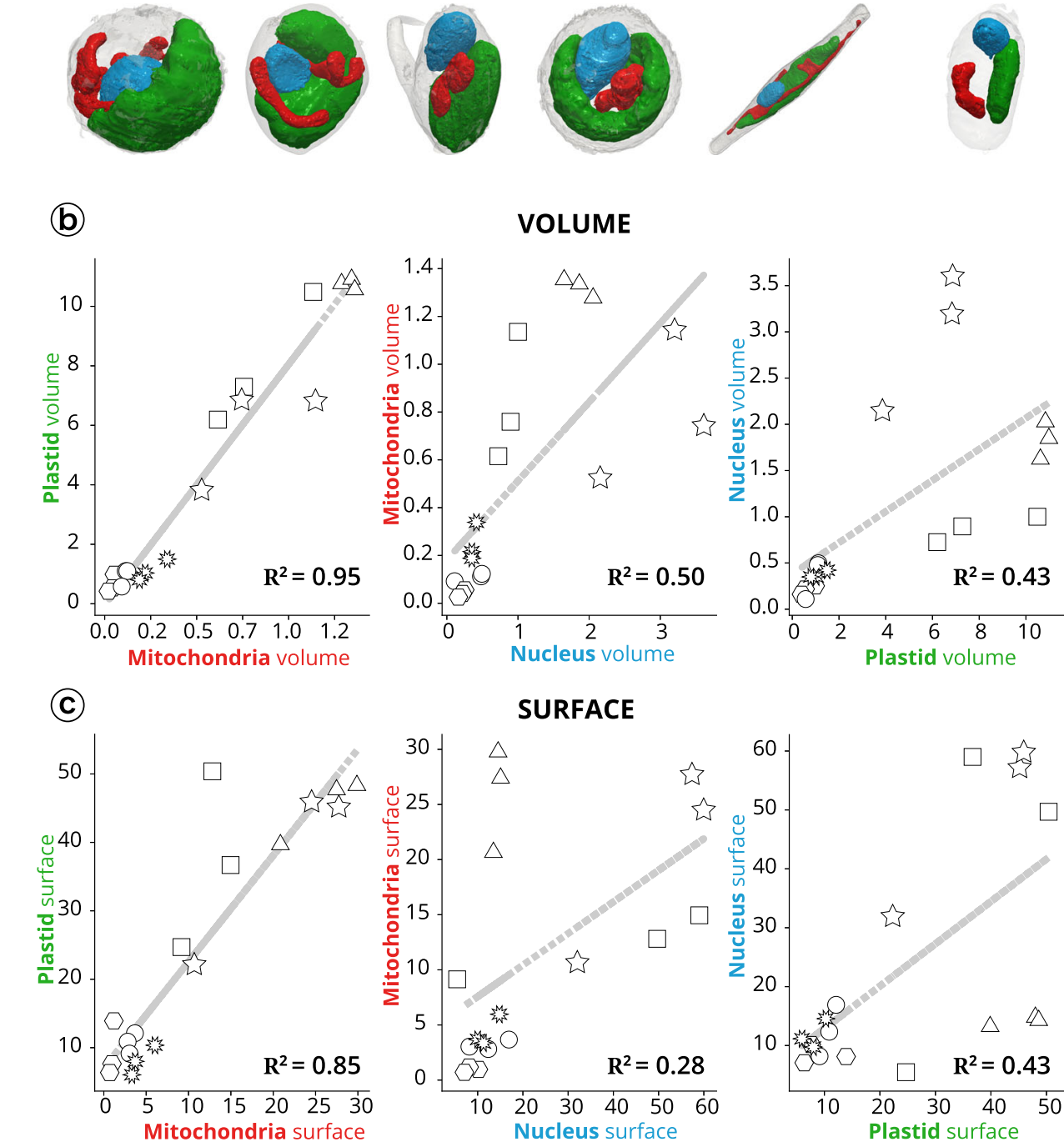

SURFACE

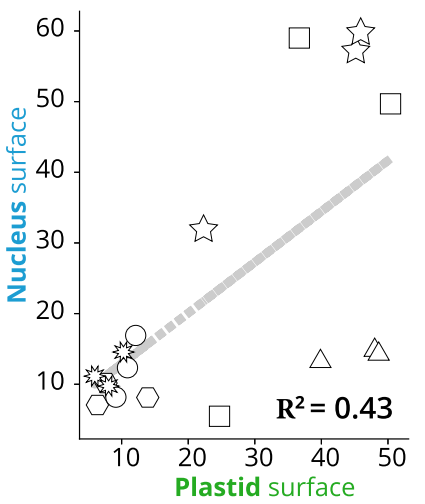

Fig. 3 Morphometric analysis of phytoplankton members. a 3D topology of the main organelles (green: plastids; red: mitochondria; blue: nuclei) in the different cell types. b Volume relationships in different subcellular compartments, as derived from quantitative analysis of microalgal 3D models. c Surface relationships in different subcellular compartments, as derived from quantitative analysis of microalgal 3D models. Three cells were considered for every taxum. Stars: Emiliania; squares: Galdieria; hexagons: Micromonas; circles: Pelagomonas; triangles: Phaeodactylum; suns: Nannochloropsis. Symbiodinium cells were not considered in this analysis, because their size, which largely exceeds the other (Supplementary Fig. 3), prevents a meaningful analysis of the volume/surface relationships.

Distances $\leq 90 \mathrm{~nm}$ may represent an 'upper limit' for contacts. Using this criterion, areas became larger in Phaeodactylum $(15.7 \pm 0.3 \%$ of the plastid surface Fig. $4 \mathrm{~b})$, and evident in all the tested organisms. However, due to the quite large intermembrane distance, areas calculated with this criterion likely represent a proximity between plastids and mitochondria, rather than genuine contact sites between the two organelles mediated by protein machineries, as observed in the case of other organelleorganelle interactions ${ }^{58-60}$.

Subcellular features of energy-managing organelles. Besides providing information on the topology of organelles, our 3D images had enough resolution to explore sub-organelle features. We exploited this possibility to investigate the possible conservation of structural architectures within plastids and mitochondria (Fig. 5 and Supplementary Fig. 4), seeking for signatures of structural constraints related to cellular energy management. Plastids were mostly occupied by thylakoid membranes and the stroma, and by the carbon-fixing pyrenoid (Fig. 5a), a Rubiscorich matrix that was absent in Pelagomonas ${ }^{46}$, Galdieria $^{61}$ and Nannochloropsis ${ }^{62}$.

In two taxa (Phaeodactylum and Emiliania), we observed thylakoids crossing the pyrenoid matrix (Fig. 5a). These pyrenoid membranes (also called pyrenoid tubules in Chlamydomonas ${ }^{6}$ ) displayed different topologies: we observed parallel stacks in the diatom (Supplementary Fig. 4) and a more branched structure in Emiliania, reminiscent of that recently reported in Chlamydomonas ${ }^{6,63}$. Micromonas and Symbiodinium contained thylakoid-free pyrenoids that were almost completely surrounded by starch sheaths (Fig. 5a). Few stalks ensure the connection between pyrenoid and the plastid, possibly to facilitate the diffusion of Rubisco substrates and products as previously proposed $^{6,64,65}$, see also the review ${ }^{66}$. Unlike Micromonas, the pyrenoid of the dinoflagellate Symbiodinium was not centred in the plastid, but instead protruded towards the cytosol, being surrounded by a shell of cytosolic rather than stromal starch ${ }^{66-68}$. 
(a)

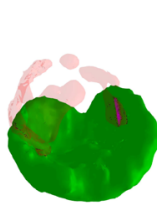

$1.8 \pm 0.8 \%$

Emiliania
Proximity between plastid and mitochondria below $30 \mathrm{~nm}$

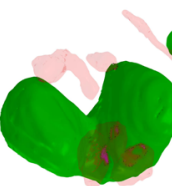

$1.7 \pm 0.9 \%$

Galdieria

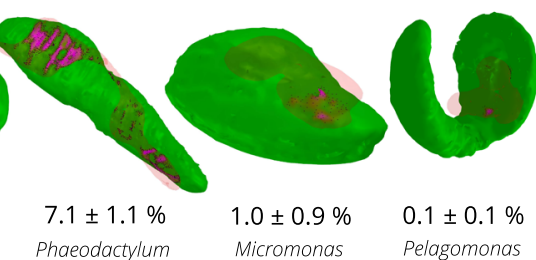

Proximity between plastid and mitochondria below 90nm

(b)
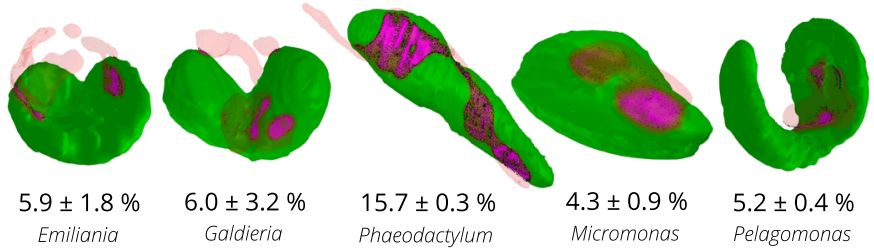

$5.2 \pm 0.4 \%$

Pelagomonas
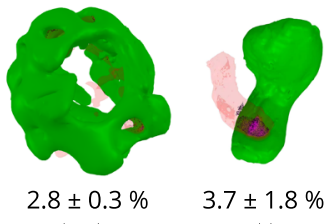

Symbiodinium Nannochoropsis

Fig. 4 Proximity between plastids and mitochondria in different phytoplankton members. Green: plastid surface. Red: mitochondria surface. Magenta: proximity surface (i.e. points at a distance $\leq 30 \mathrm{~nm}$ (panel a) or $\leq 90 \mathrm{~nm}$ (panel b) between mitochondria and plastids. Data refer to three cells \pm s.d. for every species.

(a) Plastid
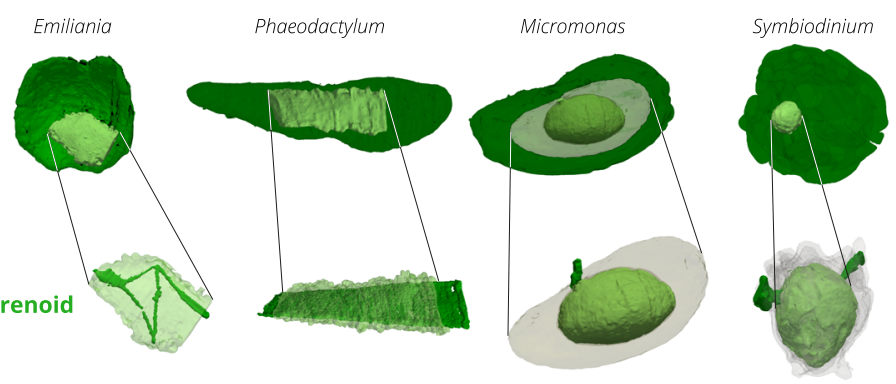

(b) Mitochondria

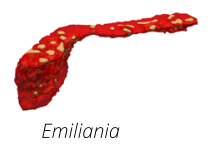

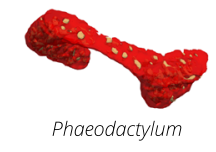

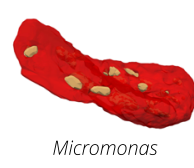

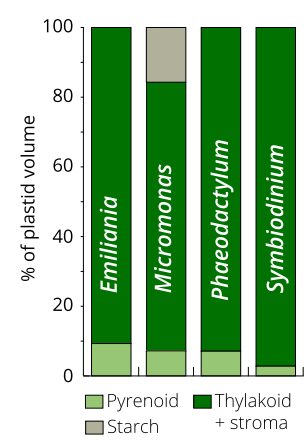

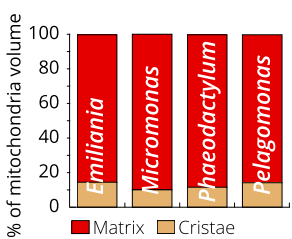

Fig. 5 Architecture of the mitochondria and plastids of different phytoplankton taxa. a Topology of the plastid. Whole plastid images and focus on the $\mathrm{CO}_{2}$-fixing compartment (pyrenoid) topology in Emiliania, Phaeodactylum, Micromonas and Symbiodinium cells. The 3D reconstruction displays the thylakoid network (dark green) crossing the pyrenoid matrix (light green). If present (Micromonas and Symbiodinium), a starch layer surrounding the pyrenoid is shown in grey. The histogram recapitulates volume occupancy by sub-plastidial structures (thylakoids, matrix, starch, pyrenoid). Note that starch is cytosolic in Symbiodinium, and therefore its volume is not considered in the graph. b Topology of mitochondrial compartments. Red: mitochondrial matrix; yellow: cristae. The histogram recapitulates volume occupancy by mitochondrial subcompartments (in the matrix and within the cristae). See Supplementary Fig. 4 for sections through plastids and mitochondria.

Despite the differences in the pyrenoid topology, the ratio of pyrenoid/plastid volumes was preserved in three out of the four microalgae lineages where this compartment was present $(7.1 \pm$ $1.2 \%, 9.3 \pm 1.4 \%, 7.2 \pm 1.2 \%$ for Phaeodactylum, Emiliania, Micromonas, respectively, Fig. 5a and Supplementary Dataset 1). This constant ratio highlights the importance of maintaining a proper balance between the subcompartments performing light harvesting (the photosynthetic membranes) and $\mathrm{CO}_{2}$ fixation (the pyrenoid). An exception to this observation is Symbiodinium, where the pyrenoid occupies a much lower fraction of the plastid volume $(2.8 \pm 0.2 \%)$. Our quantitative morphometric analysis provides a possible rationale for this difference. We found that the pyrenoid surface/volume ratio (an important parameter for gas exchange in this compartment, and therefore for $\mathrm{CO}_{2}$ assimilation) is 3-5 time higher in Phaeodactylum, Emiliania, Micromonas (20.6 $\pm 6,12.3 \pm 2.6$ and $15.1 \pm 2.4$, respectively) than in the dinoflagellate $(4.7 \pm 2.3)$. A much lower surface to volume ratio may represent a functional constraint for carbon assimilation. Therefore, we propose that the large increase in the plastid volume of Symbiodinium $\left(63.5 \pm 9.5 \mu^{3}\right.$ when compared to $11.0 \pm 0.3 \mu \mathrm{m}^{3}, 5.9 \pm 1.8 \mu \mathrm{m}^{3}$ and $0.5 \pm 0.2 \mu \mathrm{m}^{3}$, in Phaeodactylum, Emiliania and Micromonas respectively, see also Supplementary Data 1) cannot be followed by a commensurate expansion of the pyrenoid volume $\left(1.8 \pm 0.3 \mu \mathrm{m}^{3}\right.$ vs $0.8 \pm 0.1$, $0.5 \pm 0.2$ and $0.05 \pm 0.03 \mu \mathrm{m}^{3}$, respectively), to avoid an excessive decrease of the pyrenoid surface/volume ratio in this alga.

Overall, our volumetric analysis of the pyrenoid suggests that both the surface to volume ratio and the volumetric ratio between 
the plastid and the pyrenoid are important parameters for the photosynthetic metabolism. This concept of constant volumetric ratios within energy-producing organelles is corroborated by our analysis of mitochondria. In these organelles, we found that the ratio between the volume of the cristae and the matrix (Fig. 5b) is relatively constant in these cells $(11.6 \pm 2.8 \%, 14.2 \pm 2.6 \%, 14.5 \pm$ $2.9 \%, 10.1 \pm 5.9 \%$ in Phaeodactylum, Pelagomonas, Emiliania and Micromonas, respectively), despite differences in the shape (Fig. 3a and Supplementary Fig. 2) and overall volumes of their mitochondria (Fig. 2c).

Microalgal subcellular architectures and physiological responses. The finding that plastid-mitochondria interactions and suborganelle volume partitioning are relatively well conserved features of phytoplankton suggests that these subcellular features could have been evolutionarily-selected to ensure proper microalgal fitness. To test this hypothesis, we looked at possible modifications in the above-mentioned parameters upon exposing microalgae of a given species to changing environmental conditions. For these experiments, we concentrated on laboratory model algae (Phaeodactylum and Nannochloropsis), which can easily be grown in different conditions.

We first focused on Phaeodactylum cells under different light intensities, i.e. a type of environmental modification that is often experienced by diatoms ${ }^{69}$ in their natural milieu. Cells exposed to low light (LL: $40 \mu \mathrm{mol}$ photons $\mathrm{m}^{-2} \mathrm{~s}^{-1}$ ) or high light (HL: $350 \mu \mathrm{mol}$ photons $\mathrm{m}^{-2} \mathrm{~s}^{-1}$ ) led to modification of both respiratory and photosynthetic performances (Fig. 6), in line with previous reports 5 . Comparative analysis of $3 \mathrm{D}$ models of cells from
LL and HL conditions (Fig. 6a) revealed substantial changes in the morphology of the cells at the level of plastid and mitochondria.

The volume occupied by mitochondria showed an almost twofold increase in HL (from $3.9 \pm 0.2$ to $6.6 \pm 0.7 \%$ Fig. 6b), consistent with the enhanced respiratory activity. Conversely, the overall plastid volume reduced slightly from $33.7 \pm 1.8$ to $24.7 \pm 6.7 \%$. This reduction (already reported in the case of Phaeocystis antarctica ${ }^{24}$ ) was not accompanied by changes in the pyrenoid volume ( $2.4 \pm 0.6$ vs $3.2 \pm 0.9 \%$ of the cell volume) leading to an almost two-fold augmentation of the pyrenoid occupancy in the plastid (from $7.0 \pm 1.3$ to $13.2 \pm 2.5 \%$ ), at the expense of the thylakoids plus the stroma (Fig. 6b). This increase likely accounts for the augmented photosynthetic activity (from $37 \pm 10 \mathrm{nmol} \mathrm{O}_{2} \mathrm{~mL}^{-1} \mathrm{~min}^{-1}$ to $59 \pm 5 \mathrm{nmol} \mathrm{O}_{2} \mathrm{~mL}^{-1} \mathrm{~min}^{-1}$ ) observed between LL and HL acclimated cells (Fig. 6c). Indeed, photon capture by the thylakoids in HL no longer limits the photosynthetic flux, which is, instead, set by the turnover of the carbon assimilating enzymes. The finding that plastidmitochondrial proximity increased between HL and LL cells $(+36 \pm 14 \%$ at $\leq 30 \mathrm{~nm}$ and $+25 \pm 7 \%$ at $\leq 90 \mathrm{~nm}$, Fig. $6 \mathrm{~d})$ also provides a possible rationale for the enhanced photosynthesis observed in HL cells. Indeed, previous work showed that organelle interactions are an advantage for carbon assimilation in diatoms, to facilitate energetic interactions between the two cell engines 5 .

Next, we compared the physiology and subcellular features of Nannochloropsis cells exposed to two trophic conditions. Previous studies highlighted the ability of this alga to metabolize external carbon sources under photosynthetic conditions (mixotrophy) to improve growth ${ }^{70-72}$. We reproduced the reported growth enhancement when cells were shifted from phototrophy (without

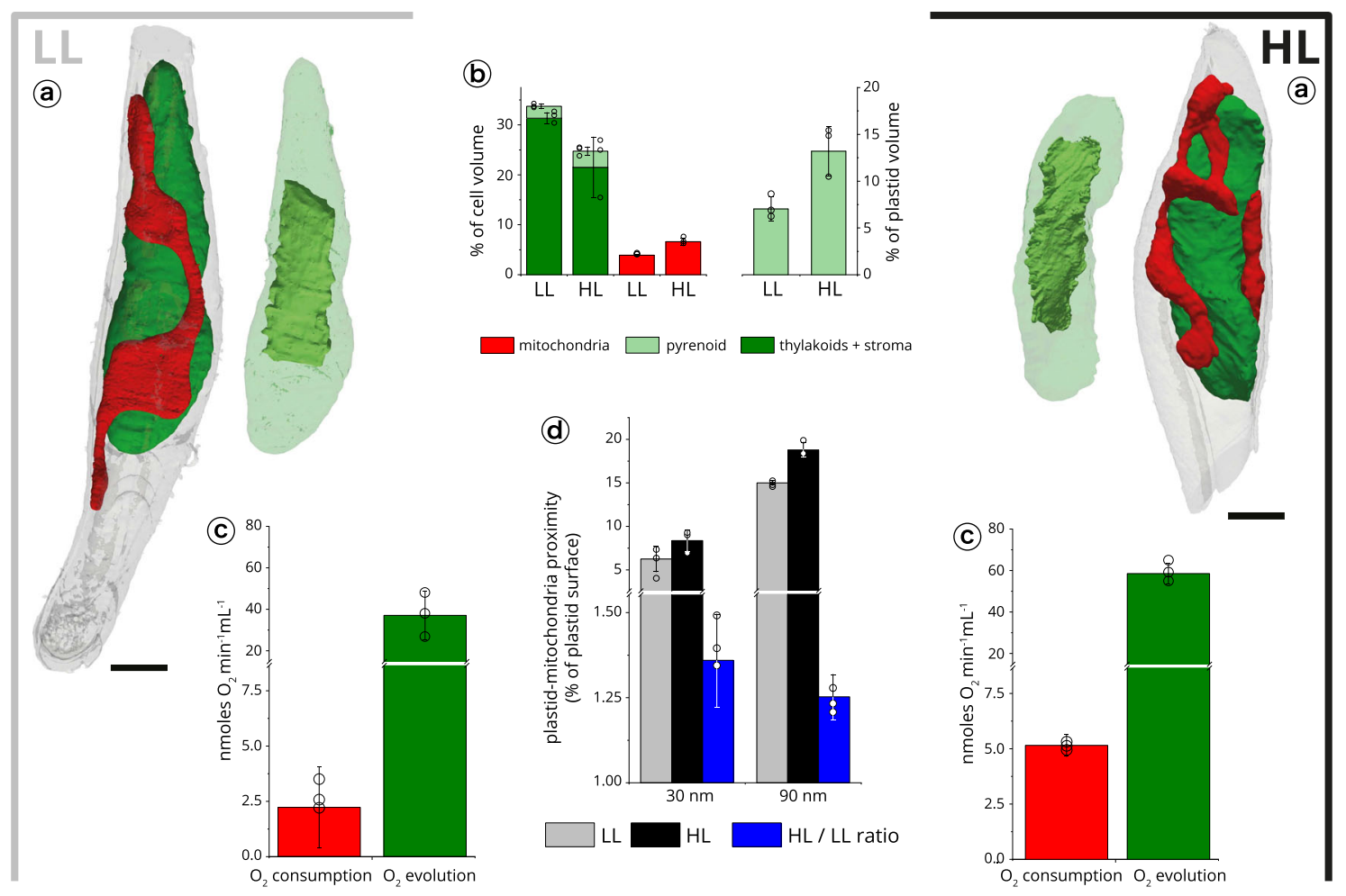

Fig. 6 Structural analysis of light acclimation in Phaeodactylum tricornutum. a Cells were imaged at two different light regimes: LL (40 $\mu$ mol photons $\mathrm{m}^{-2} \mathrm{~s}^{-1}$, left) and $\mathrm{HL}\left(350 \mu \mathrm{mol}\right.$ photons $\mathrm{m}^{-2} \mathrm{~s}^{-1}$, right). Scale bar: $1 \mu \mathrm{m} . \mathbf{b}$ Volume occupancy by the plastids (dark green), mitochondria (red) and pyrenoid (light green) in the two conditions. Data refer to three cells \pm s.d. for each growth condition. c Respiratory activities (red) and photosynthetic capacities (green) are indicated for LL (left) and HL (right) cells. Data refer to three biological samples \pm s.d. for each growth condition. d Plastidmitochondria proximity surface points in $\mathrm{LL}$ and $\mathrm{HL}$ cells, measured at $\leq 30 \mathrm{~nm}$ (grey) and $\leq 90 \mathrm{~nm}$ (black). At both distances, proximity areas points are increased by around $25 \%$ (blue) upon $\mathrm{HL}$ transition. Data refer to three cells \pm s.d. for each growth condition. 


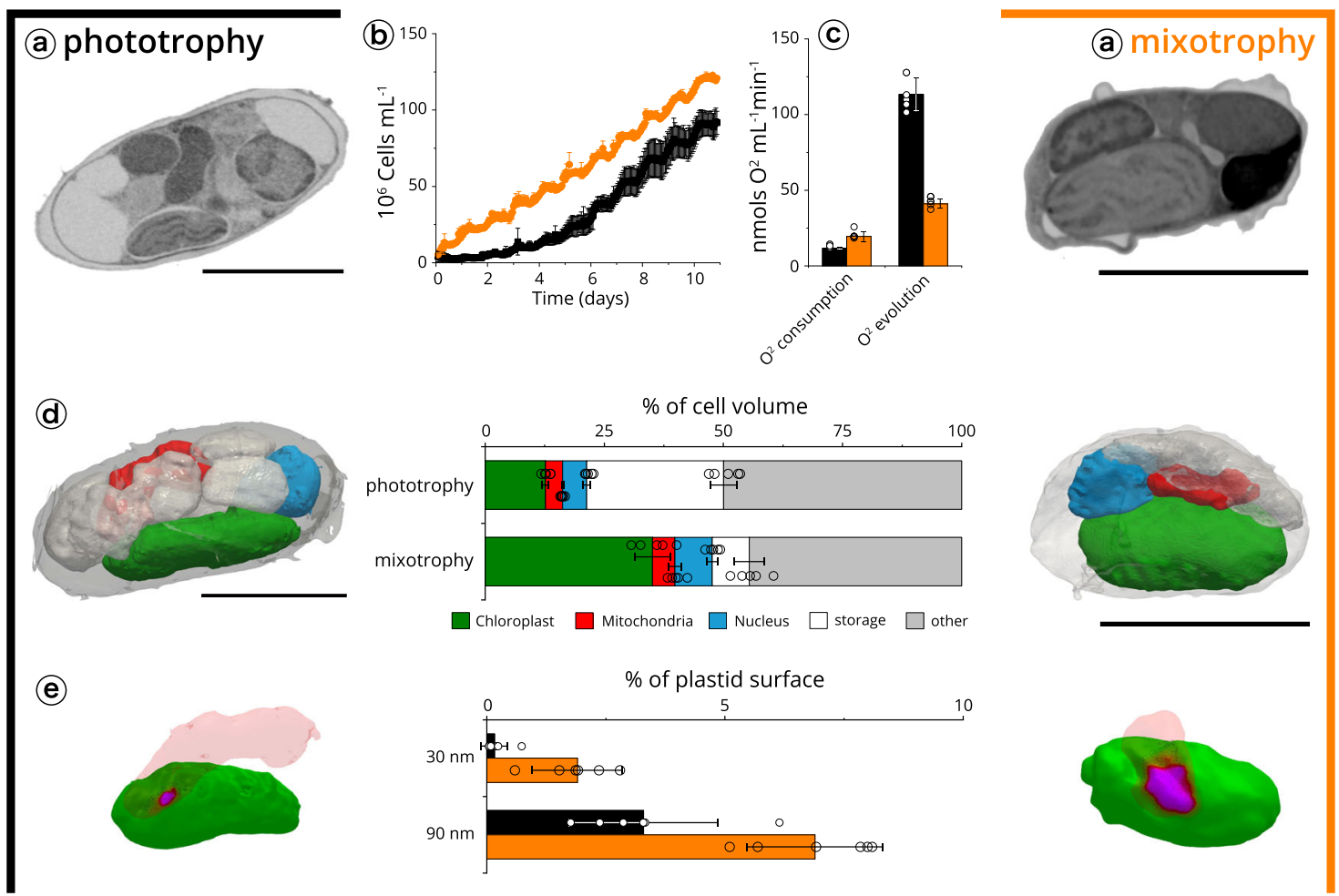

Fig. 7 Plastid-mitochondria interactions are modified by trophic regimes in Nannochloropsis. a Cells were imaged after growth in phototrophic (left) and mixotrophic (right) conditions. Sections are representatives micrographs of an experiment repeated three times with similar results. Scale bar: $2 \mu \mathrm{m}$. $\mathbf{b}$ Cell growth in phototrophic conditions (black) and mixotrophic conditions (orange). Data refer to three biological samples \pm s.d. for each growth condition. c Oxygen consumption (respiration) and evolution (photosynthesis). Data refer to six biological samples \pm s.d. for each growth condition. $\mathbf{d}$ Cell-volume occupancy by the different subcellular compartments in different microalgal cells. Green: plastid; red: mitochondria; blue: nuclei; white: storage vesicles; grey: other. Data refer to five cells \pm s.d. for each growth condition. Scale bar: $2 \mu \mathrm{m}$. e analysis of proximity surface points (magenta) between plastid (green) and mitochondria (red). Data refer to five cells \pm s.d. for each growth condition.

organic carbon) to a carbon-rich medium ${ }^{73}$, and found that changes in the trophic lifestyle of this alga were also accompanied by substantial physiological and morphological changes (Fig. 7a). In particular, growing algae in mixotrophy enhanced their respiratory capacity (from $11.5 \pm 0.8$ to $18.9 \pm 2.9 \mathrm{nmol} \mathrm{O}_{2} \mathrm{~mL}^{-1} \mathrm{~min}^{-1}$, Fig. 7c) while decreasing their photosynthetic activity (from $113.2 \pm$ $11.1 \mathrm{nmol} \mathrm{O}_{2} \mathrm{~mL}^{-1} \mathrm{~min}^{-1}$ to $41.0 \pm 3.2 \mathrm{nmol} \mathrm{O}_{2} \mathrm{~mL}^{-1} \mathrm{~min}^{-1}$, Fig. 7c). These changes were accompanied by a modification in the cell organization. Phototrophic cells were largely filled with reserve vesicles $(28.7 \pm 2.9 \%$ of the cell volume), thereby reducing the volume left to the organelles $(21.3 \pm 0.2 \%)$. The bulkiness of reserve vesicles was reduced in mixotrophic cell $(7.8 \pm 3.4 \%)$, in which the volume occupied by organelles (Fig. $7 \mathrm{~d}$ ) recovered a value $(47.7 \pm 1.1 \%)$ similar to the one observed in other algae in phototrophic conditions (Fig. 2). This reduced storage capacity in mixotrophic cells may stem from a higher consumption of lipid reserves $^{73}$, caused by the less favourable balance between photosynthesis-which produces reserves and respiration-which consumes them.

Plastid-mitochondria proximity increased in cells acclimated to mixotrophy (Fig. 7e). The effect was substantial when calculated using an organelle distance of $\leq 30 \mathrm{~nm}$ (from $0.16 \pm 0.25$ to $1.8 \pm$ 0.7 ) and still significant (two-fold) at $\leq 90 \mathrm{~nm}$ (from $3.3 \pm 1.5$ to $6.9 \pm 1.2$ ). Although the proximity surface between the organelles is small, its increase could be relevant in the frame of the observed physiological changes. Plastid-mitochondria proximity may facilitate energy exchanges between the organelles in Nannochloropsis, to readjust the balance between the two cell organelles according to the environmental conditions. Alternatively, proximity could mediate lipid exchange between plastids and mitochondria ${ }^{53}$, contributing to the structural changes observed between the two trophic conditions.

By optimizing sample preparation, image acquisition, segmentation and $3 \mathrm{D}$ reconstruction, for a quantitative FIB-SEM tomography workflow, we have demonstrated that 3D whole-cell models can be efficiently created, providing a unique resource to quantitatively compare cellular morphological features. Our analysis of phytoplankton pinpoints conserved features (cellvolume fractions occupied by the main organelles, plastidmitochondria proximity) and highlights the existence of constant surface/volumetric ratios within the energy-producing organelles, exemplified by the surface to volume ratio in mitochondria and in the pyrenoid. These characteristics imply the existence of topological constraints, presumably related to organelle function at the level of energy management for carbon assimilation. Our investigations of light acclimation in Phaeodactylum cells and acclimation to different trophic lifestyles in Nannochloropsis are consistent with this hypothesis, as topological modifications in their cellular engines accompanied physiological changes. These data highlight the intimate links between cellular structures, energy balance and physiological responses. Associating the approach we have developed with cryo-electron tomography, with chemical imaging ${ }^{74}$, or with correlative microscopic studies ${ }^{75,76}$ will vastly improve investigations of phytoplankton as well as vascular plants, e.g. to study the impacts of climate change scenarios ${ }^{77}$. It will be critical to assess how changes in temperature and nutrient availability in the oceans affect the subcellular features and acclimation capacity of these key phototrophic microorganisms, so as to predict their future activity at the global scale. 


\section{Methods}

Species. The species used in this work (Supplementary Table 1) were chosen on the basis of their representativeness of phytoplankton taxa that are ecologically relevant or of their ability to successfully grow in variable laboratory conditions.

Algal cultivation. Phaeodactylum CCAP 1055/3 was obtained from the Culture Collection of Algae and Protozoa, Scottish Marine institute, UK. Cells were grown in artificial seawater $(\mathrm{ESAW})^{78}$ using ten times enriched nitrogen and phosphate sources ( $5.49 \mathrm{mM} \mathrm{NaNO}$ and $0.224 \mathrm{mM} \mathrm{NaH} \mathrm{PO}_{4}$; called "10X ESAW"79). Cells were grown in $50 \mathrm{~mL}$ flasks in a growth cabinet (Minitron, Infors HT, Switzerland), at $19^{\circ} \mathrm{C}$, a light intensity of $40 \mu \mathrm{mol}$ photon $\mathrm{m}^{-2} \mathrm{~s}^{-1}$, a 12 -h light /12-h dark photoperiod (unless otherwise specified) and shaking at $100 \mathrm{rpm}$. Galdieria SAG21.92 was obtained from the University of Dusseldorf (Germany) and was grown in sterile 2XGS modified Allen medium, $\mathrm{pH} 2.0$ (ref. ${ }^{80}$ ) at $42{ }^{\circ} \mathrm{C}$ under the same light conditions. Cells were grown in $250 \mathrm{~mL}$ flasks ( $50 \mathrm{~mL}$ culture volume). Nannochloropsis CCMP526 was also cultivated in artificial seawater (10X ESAW). Photoperiod was 12-h light /12-h dark. Cells were shifted from phototrophic to mixotrophic conditions through the addition of 5\% Lysogeny Broth (LB) to the growth medium. Micromonas RCC 827, Pelagomonas RCC 100, Emiliania RCC 909 (grown in $\mathrm{K}$ medium at $20^{\circ} \mathrm{C}$ ), and Symbiodinium RCC 4014 (grown in $f / 2$ medium at $20^{\circ} \mathrm{C}$ ) were obtained from the Roscoff Culture Collection (http://www. roscoff-culture-collection.org/) ${ }^{81}$ and maintained at a light intensity of $60-80 \mu \mathrm{mol}$ photons $\mathrm{m}^{-2} \mathrm{~s}^{-1}$, in a 12-h light /12-h dark photoperiod, without shaking.

Nannochloropsis growth was measured following changes in the culture optical density at $650 \mathrm{~nm}$. Changes were calibrated with cell numbers in both control and mixotrophic cultures.

Photophysiology measurements. Oxygen exchanges were measured with a Clarktype electrode (Hansatech Instruments, UK) at $20^{\circ} \mathrm{C}$, with respiration and gross photosynthesis quantified by measuring the slope in the dark and upon light exposure (intensity $300 \mu \mathrm{mol}$ photons $\mathrm{m}^{-2} \mathrm{~s}^{-1}$ ), respectively.

The parameter $\mathrm{Fv} / \mathrm{Fm}$ (maximum yield of photosystem II photochemistry) ${ }^{82}$ was used to compare the photosynthetic capacity of the tested strain with earlier data in the literature, as a proxy for their physiological state. $F_{\mathrm{v}} / F_{\mathrm{m}}$ was measured with a Speedzen 3 chlorophyll fluorescence imaging setup (Biologic, France). It was calculated as $\left(F_{\mathrm{m}}-F_{0}\right) / F_{\mathrm{m}}$, where $F_{0}$ is the minimum fluorescence yield, determined at open photosystem II reactions centres and $F_{\mathrm{m}}$ is the maximum fluorescence yield, measured upon closing the photosystem II reaction centres with a short $(150 \mathrm{~ms})$ saturating light pulse.

Sample preparation for electron microscopy. Sample preparation protocols were adapted from reference ${ }^{41}$ to optimize the contrast for 3D electron microscopy imaging and therefore facilitate image segmentation through pixel classification. Live cells were cryofixed using high-pressure freezing (EM HPM100, Leica, Germany) in which cells were subjected to a pressure of $210 \mathrm{MPa}$ at $-196^{\circ} \mathrm{C}$, followed by freeze substitution (EM ASF2, Leica, Germany). Prior to cryo fixation, the microalgal cultures were concentrated by gentle centrifugation for $10 \mathrm{~min}$ $(1000 \mathrm{~g})$. For the freeze substitution, a mixture $2 \%(\mathrm{w} / \mathrm{v})$ osmium tetroxide and $0.5 \%(\mathrm{w} / \mathrm{v})$ uranyl acetate in dried acetone was used. The freeze-substitution machine was programmed as follows: $60-80 \mathrm{~h}$ at $-90^{\circ} \mathrm{C}$, heating rate of $2{ }^{\circ} \mathrm{C} \mathrm{h}^{-1}$ to $-60{ }^{\circ} \mathrm{C}(15 \mathrm{~h}), 10-12 \mathrm{~h}$ at $-60{ }^{\circ} \mathrm{C}$, heating rate of $2{ }^{\circ} \mathrm{Ch}^{-1}$ to $-30^{\circ} \mathrm{C}(15 \mathrm{~h})$, and $10-12 \mathrm{~h}$ at $-30^{\circ} \mathrm{C}$, quickly heated to $0^{\circ} \mathrm{C}$ for $1 \mathrm{~h}$ to enhance the staining efficiency of osmium tetroxide and uranyl acetate and then back at $-30^{\circ} \mathrm{C}$. The cells were then washed four times in anhydrous acetone for $15 \mathrm{~min}$ each at $-30^{\circ} \mathrm{C}$ and gradually embedded in anhydrous araldite resin. A graded resin/acetone $(\mathrm{v} / \mathrm{v})$ series was used (30,50 and $70 \%$ resin) with each step lasting $2 \mathrm{~h}$ at increased temperature: $30 \%$ resin/acetone bath from $-30^{\circ} \mathrm{C}$ to $-10^{\circ} \mathrm{C}, 50 \%$ resin/acetone bath from $-10^{\circ} \mathrm{C}$ to $10^{\circ} \mathrm{C}, 70 \%$ resin/acetone bath from $10^{\circ} \mathrm{C}$ to $20^{\circ} \mathrm{C}$. Samples were then placed in $100 \%$ resin for $8-10 \mathrm{~h}$ and in $100 \%$ resin with the accelerator BDMA for $8 \mathrm{~h}$ at room temperature. Resin polymerization finally occurred at $65^{\circ} \mathrm{C}$ for $48 \mathrm{~h}$.

FIB-SEM acquisition imaging. Focused ion beam (FIB) tomography was performed with either a Zeiss NVision 40 or a Zeiss CrossBeam 550 microscope (Zeiss, Germany), both equipped with Fibics Atlas 3D software for tomography (Supplementary Fig. 1a). The resin block containing the cells was fixed on a stub with carbon paste, and surface-abraded with a diamond knife in a microtome to obtain a perfectly flat and clean surface. The entire sample was metallized with $4 \mathrm{~nm}$ of platinum to avoid charging during the observations. Inside the FIB-SEM, a second platinum layer $(1-2 \mu \mathrm{m})$ was deposited locally on the analysed area to mitigate possible curtaining artefacts. The sample was then abraded slice by slice with the $\mathrm{Ga}^{+}$ion beam (generally with a current of $700 \mathrm{nA}$ at $30 \mathrm{kV}$ ). Each freshly exposed surface was imaged by scanning electron microscopy (SEM) at $1.5 \mathrm{kV}$ and with a current of $\sim 1 \mathrm{nA}$ using the in-lens EsB backscatter detector. For algae, we generally used the simultaneous milling and imaging mode for better stability, and with an hourly automatic correction of focus and astigmatism. For each slice, a thickness of $8 \mathrm{~nm}$ was removed, and the SEM images were recorded with a pixel size of $8 \mathrm{~nm}$, providing an isotropic voxel size of $8 \times 8 \times 8 \mathrm{~nm}^{3}$. Whole volumes were imaged with 800-1000 frames, depending on the species. Due to its reduced cell dimensions, the voxel size was reduced to $4 \times 4 \times 4 \mathrm{~nm}^{3}$ in the case of Micromonas, resulting in higher resolution datasets with approximately 350-500 frames/cell.

Image processing. As a first step of image processing, regions of interest (ROIs) containing cells were cropped from the full image stack. This was followed by image registration (stack alignment), noise reduction, semi-automatic segmentation of the ROIs, 3D reconstruction of microalgae cells and morphometric analysis. Several problems may be encountered during these steps. Raw stacks consist of big data (50-100 GB for the whole imaged volume, containing several cells) that do not necessarily fit into the computer main memory (RAM). Moreover, cryo-substituted cells generate less contrasted images than cells prepared with chemical fixation. Therefore, the first step in building a robust 3D model consists in 'isolating' a given ROI (e.g. an organelle) from other compartments, to obtain a smaller stack size that can be easily worked with (in practice, we worked with substacks that were around $10 \%$ of the original stack size).

Single cells were isolated by cropping in three dimensions using the open software Fiji (https://imagej.net/Fiji, Supplementary Fig. 1a). Image misalignment was corrected using the template matching ("align slices in stack") option implemented in Fiji. This function finds the most similar image pattern in every slice and translates them to align the landmark pattern across the stack (https:// sites.google.com/site/qingzongtseng/template-matching-ij-plugin) (Supplementary Movies 1-9). Aligned image stacks were filtered to remove noise using Python ${ }^{83}$ and OpenCV (https://opencv.org). Filtering techniques were chosen to highlight contours while removing noise in the images. Depending on the species, we found that the osmium staining was not homogeneously distributed. Therefore, it was not possible to filter raw datasets of every species with the same method. Based on the effectiveness in highlighting organelle boundaries, different filters were used for the different microalgae (Supplementary Fig. 1b). Application of a linear Gaussian filter followed by sharpening to remove noise and enhance contours, which is widely used and easy to implement ${ }^{84}$, was used to process raw datasets of Emiliania, Micromonas, Phaeodactylum and Pelagomonas. However, this method was less effective when applied to raw datasets of Galdieria and Symbiodinium, where using the median filter proved to be a better de-noising option. These choices reflect the different cellular features and biochemical composition of each taxon (e.g. the presence of a thick cell wall in Galdieria), which results in variable contrast.

Segmentation. Segmentation of organelles, vesicular networks, vacuoles and storage compartments was carried out with 3D Slicer software ${ }^{85}$ (www.slicer.org, Supplementary Fig. 1c), using a manually-curated, semi-automatic pixel clustering mode ( 3 to 10 slices are segmented simultaneously for a given ROI). We assigned colours to the ROIs using paint tools and adjusted the threshold range for image intensity values. The ROIs were annotated and the corresponding label map was run into the model maker module from 3D slicer (Supplementary Fig. 1c), to generate corresponding 3D models that were exported in different formats (. stl, obj, vtk, ply, mtl). For further analysis, we used the.stl mesh, which proved to be most suitable for 3D analysis in our workflow (Supplementary Table 2).

3D reconstructed model. A 3D filtering process was needed to refine the model and reduce the size of the file (see Supplementary Table 2). In our case, 3D models generated by $3 \mathrm{D}$ Slicer were imported into the open source software MeshLab ${ }^{86,87}$ which automatically removed some 'isolated islands'. Models were further edited manually within MeshLab to eliminate remaining isolated islands erroneously annotated as ROIs. We also performed a remeshing process to facilitate 3D modelling, visualization and animation. Using MeshLab, we simplified meshes ('mesh decimation', Supplementary Fig. 1d) to reduce the model nodes and faces down to $25 \%$ of the original data without modifying morphometric values, such as surfaces and volumes (Supplementary Table 2). Every 3D model was imported into Paraview $^{88}$ (Supplementary Fig. 1d) to visualize 3D objects and understand their relationships. Blender (www.blender.org) was used for object animation (Supplementary Movie 10).

Morphometric evaluations. Measurement of volumes, surface area, and the minimum distance between meshes) were performed using Numpy-STL (https:// pypi.org/project/numpy-stl/) and TRIMESH (https://trimsh.org/trimesh.html) packages of Python (Supplementary Table 3). This Python package is faster than MeshLab, with obvious advantages in terms of analysis of large files ( $>500 \mathrm{MB})$.

Surface and volume measurements. Surfaces and volumes were computed using the discrete mesh geometry, with surfaces computed directly from mesh triangles and volumes computed from the signed volume of individual tetrahedrons, assuming a closed surface (watertight mesh, Supplementary Fig. 1e). Briefly, to compute the surface, we iterated over all the triangles of the mesh. The computation of the cross product between two edges of a given triangle gives a vector whose magnitude is twice the area of said triangle. Then, the sum of all these areas provides the total surface area of the mesh. We then computed the signed volume of all tetrahedrons, which goes from the origin $(0,0,0)$ to each triangle present in the mesh. Assuming a closed surface (watertight mesh), summing all those volumes gives the volume of the mesh ${ }^{89}$. A simple implementation of those algorithms is provided in Supplementary dataset 2 . 
Distance between organelles. Using the Trimesh Python module, the minimal distance between two meshes was calculated based on the closest points between two triangular meshes. Hence, the surface proximity areas were quantified based on: (i) calculating the minimal distance between each vertex of the plastid mesh to the mitochondria mesh (for 3 cells of every species), and then by (ii) gathering mesh vertices according to a given distance threshold to generate proximity surfaces. Two distance thresholds were chosen for this analysis: $\leq 30 \mathrm{~nm}$, the 'average' one, to define possible contact points ${ }^{54-56}$ and $\leq 90 \mathrm{~nm}$, defining the 'upper limit' for organelle proximity ${ }^{57,90}$. The corresponding surfaces were then compared to the total plastid surface (Supplementary dataset 3).

Reporting summary. Further information on research design is available in the Nature Research Reporting Summary linked to this article.

\section{Data availability}

The authors declare that all the data supporting the findings of this study are available within the paper and in its supplementary information files. Raw FIB-SEM stacks are available at https://www.ebi.ac.uk/biostudies/studies/S-BSST575. Source data are provided with this paper.

\section{Code availability}

The computer codes supporting the findings of this study are available in the supplementary data 2 and supplementary data 3 . The proximity distance computation code is available at: https://gitlab.com/clariaddy/mindist. The metrics computation code is available at: https://gitlab.com/clariaddy/stl_statistics.

Received: 5 June 2020; Accepted: 12 January 2021;

Published online: 16 February 2021

\section{References}

1. Field, C. B., Behrenfeld, M. J., Randerson, J. T. \& Falkowski, P. Primary production of the biosphere: integrating terrestrial and oceanic components. Science 281, 237-240 (1998).

2. Sibbald, S. J. \& Archibald, J. M. Genomic insights into plastid evolution. Genome Biol. Evol. 12, 978-990 (2020).

3. Not, F. et al. Diversity and ecology of eukaryotic marine phytoplankton. $A d v$. Botanical Res. 64, 1-53 (2012).

4. de Vargas, C. et al. Ocean plankton. Eukaryotic plankton diversity in the sunlit ocean. Science 348, 1261605 (2015).

5. Bailleul, B. et al. Energetic coupling between plastids and mitochondria drives CO2 assimilation in diatoms. Nature 524, 366-369 (2015).

6. Engel, B. D. et al. Native architecture of the Chlamydomonas chloroplast revealed by in situ cryo-electron tomography. eLife 4, e04889 (2015).

7. Andersen, R. A., Bailey, J. C., Decelle, J. \& Probert, I. Phaeocystis rex sp. nov. (Phaeocystales, Prymnesiophyceae): a new solitary species that produces a multilayered scale cell covering. Eur. J. Phycol. 50, 207-222 (2015).

8. Embleton, K. V., Gibson, C. E. \& Heaney, S. I. Automated counting of phytoplankton by pattern recognition: a comparison with a manual counting method. J. Plankton Res. 25, 669-681 (2003).

9. Rodenacker, K., Hense, B., Jutting, U. \& Gais, P. Automatic analysis of aqueous specimens for phytoplankton structure recognition and population estimation. Microsc. Res. Tech. 69, 708-720 (2006).

10. Schulze, K., Tillich, U. M., Dandekar, T. \& Frohme, M. PlanktoVision-an automated analysis system for the identification of phytoplankton. BMC Bioinformatics 14, 115 (2013).

11. Sosik, H. M. \& Olson, R. J. Automated taxonomic classification of phytoplankton sampled with imaging-in-flow cytometry. Limnol. Oceanogr. Methods 5, 204-216 (2007).

12. Hense, B. A., Gais, P., Jutting, U., Scherb, H. \& Rodenacker, K. Use of fluorescence information for automated phytoplankton investigation by image analysis. J. Plankton Res. 30, 587-606 (2008).

13. Colin, S. et al. Quantitative 3D-imaging for cell biology and ecology of environmental microbial eukaryotes. eLife 6, e26066 (2017).

14. Baumeister, W. Electron tomography: towards visualizing the molecular organization of the cytoplasm. Curr. Opin. Struct. Biol. 12, 679-684 (2002).

15. Phan, S. et al. 3D reconstruction of biological structures: automated procedures for alignment and reconstruction of multiple tilt series in electron tomography. Adv. Struct. Chem. Imaging 2, 1-18 (2016).

16. Titze, B. \& Genoud, C. Volume scanning electron microscopy for imaging biological ultrastructure. Biol. Cell 108, 307-323 (2016).

17. Mineyuki, Y. 3D image analysis of plants using electron tomography and micro-CT. Microscopy 63, i8-i9 (2014).
18. Liang, Z. et al. Thylakoid-bound polysomes and a dynamin-related protein, FZL, mediate critical stages of the linear chloroplast biogenesis program in greening Arabidopsis cotyledons. Plant Cell 30, 1476-1495 (2018).

19. Austin, J. R. \& Staehelin, L. A. Three-dimensional architecture of grana and stroma thylakoids of higher plants as determined by electron tomography. Plant Physiol. 155, 1601-1611 (2011).

20. Daum, B., Nicastro, D., Austin, J., McIntosh, J. R. \& Kühlbrandt, W. Arrangement of photosystem II and ATP synthase in chloroplast membranes of spinach and pea. Plant Cell 22, 1299-1312 (2010).

21. Kouřil, R., Oostergetel, G. T. \& Boekema, E. J. Fine structure of granal thylakoid membrane organization using cryo electron tomography. Biochim. Biophys. Acta (BBA)-Bioenerg. 1807, 368-374 (2011).

22. Kowalewska, Ł., Mazur, R., Suski, S., Garstka, M. \& Mostowska, A. Three dimensional visualization of the tubular-lamellar transformation of the internal plastid membrane network during runner bean chloroplast biogenesis. Plant Cell 28, 875-891 (2016).

23. Shimoni, E., Rav-Hon, O., Ohad, I., Brumfeld, V. \& Reich, Z. Threedimensional organization of higher-plant chloroplast thylakoid membranes revealed by electron tomography. Plant Cell 17, 2580-2586 (2005).

24. Moisan, T. A., Ellisman, M. H., Buitenhuys, C. W. \& Sosinsky, G. E. Differences in chloroplast ultrastructure of Phaeocystis antarctica in low and high light. Mar. Biol. 149, 1281-1290 (2006).

25. Moisan, T. A. \& Mitchell, B. G. Photophysiological acclimation of Phaeocystis antarctica Karsten under light limitation. Limnol. Oceanogr. 44, 247-258 (1999).

26. Ota, S. et al. Highly efficient lipid production in the green alga Parachlorella kessleri: draft genome and transcriptome endorsed by whole-cell 3D ultrastructure. Biotechnol. Biofuels 9, 13 (2016).

27. Ota, S. et al. Deciphering the relationship among phosphate dynamics, electron-dense body and lipid accumulation in the green alga Parachlorella kessleri. Sci. Rep. 6, 1-11 (2016).

28. Wayama, M. et al. Three-dimensional ultrastructural study of oil and astaxanthin accumulation during encystment in the green alga Haematococcus pluvialis. PloS ONE 8, e53618 (2013).

29. Harwood, R. et al. Cell and chloroplast anatomical features are poorly estimated from 2D cross-sections. N. Phytologist 225, 2567-2578 (2020).

30. Kittelmann, M., Hawes, C. \& Hughes, L. Serial block face scanning electron microscopy and the reconstruction of plant cell membrane systems. J. Microsc. 263, 200-211 (2016).

31. Pain, C., Kriechbaumer, V., Kittelmann, M., Hawes, C. \& Fricker, M. Quantitative analysis of plant ER architecture and dynamics. Nat. Commun. 10, 1-15 (2019).

32. Rigort, A., Villa, E., Bäuerlein, F. J., Engel, B. D. \& Plitzko, J. M. in Methods in Cell Biology (eds Muller-Reichert, T. \& Verkade, P.) (Elsevier, 2012).

33. Schaffer, M. et al. Cryo-focused ion beam sample preparation for imaging vitreous cells by cryo-electron tomography. Bio Protoc. 5, e1575 (2015).

34. Wietrzynski, W. et al. Charting the native architecture of Chlamydomonas thylakoid membranes with single-molecule precision. eLife 9, e53740 (2020).

35. Oi, T. et al. Three-dimensional intracellular structure of a whole rice mesophyll cell observed with FIB-SEM. Ann. Bot. 120, 21-28 (2017).

36. Yamane, K. et al. Three-dimensional ultrastructure of chloroplast pockets formed under salinity stress. Plant Cell Environ. 41, 563-575 (2018).

37. García-Cerdán, J. G. et al. Chloroplast Sec14-like 1 (CPSFL1) is essential for normal chloroplast development and affects carotenoid accumulation in Chlamydomonas. Proc. Natl Acad. Sci. 117, 12452-12463 (2020).

38. Xu, C. S. et al. Enhanced FIB-SEM systems for large-volume $3 \mathrm{D}$ imaging. eLife 6, e25916 (2017).

39. Flori, S. et al. Plastid thylakoid architecture optimizes photosynthesis in diatoms. Nat. Commun. 8, 15885 (2017).

40. Flori, S., Jouneau, P. H., Finazzi, G., Marechal, E. \& Falconet, D. Ultrastructure of the periplastidial compartment of the diatom Phaeodactylum tricornutum. Protist 167, 254-267 (2016).

41. Decelle, J. et al. Algal remodeling in a ubiquitous planktonic photosymbiosis. Curr. Biol. 29, 968-978 e964 (2019).

42. Sviben, S. et al. A vacuole-like compartment concentrates a disordered calcium phase in a key coccolithophorid alga. Nat. Commun. 7, 11228 (2016)

43. Jantschke, A. et al. Anhydrous $\beta$-guanine crystals in a marine dinoflagellate: structure and suggested function. J. Struct. Biol. 207, 12-20 (2019).

44. Jantschke, A., Pinkas, I., Schertel, A., Addadi, L. \& Weiner, S. Biomineralization pathways in calcifying dinoflagellates: Uptake, storage in $\mathrm{MgCaP}-$ rich bodies and formation of the shell. Acta Biomaterialia 102, 427-439 (2020).

45. Gal, A. et al. Native-state imaging of calcifying and noncalcifying microalgae reveals similarities in their calcium storage organelles. Proc. Natl Acad. Sci. USA 115, 11000-11005 (2018).

46. Andersen, R. A., Saunders, G. W., Paskind, M. P. \& Sexton, J. P. Ultrastructure and $18 \mathrm{~s}$ ribosomal-Rna gene sequence for pelagomonas-calceolata Gen Et 
Sp-Nov and the description of a new algal class, the pelagophyceae classis nov. J. Phycol. 29, 701-715 (1993).

47. Simionato, D. et al. The response of Nannochloropsis gaditana to nitrogen starvation includes de novo biosynthesis of triacylglycerols, a decrease of chloroplast galactolipids, and reorganization of the photosynthetic apparatus. Eukaryot. Cell 12, 665-676 (2013).

48. Lopes Dos Santos, A. et al. Chloropicophyceae, a new class of picophytoplanktonic prasinophytes. Sci. Rep. 7, 14019 (2017).

49. Lupette, J. et al. The architecture of lipid droplets in the diatom Phaeodactylum tricornutum. Algal Res. 38, 101415 (2019).

50. Mustardy, L. \& Garab, G. Granum revisited. A three-dimensional model-where things fall into place. Trends Plant Sci. 8, 117-122 (2003).

51. Bereiter-Hahn, J. \& Vöth, M. Dynamics of mitochondria in living cells: shape changes, dislocations, fusion, and fission of mitochondria. Microsc. Res. Tech. 27, 198-219 (1994).

52. Kim, J. et al. Flux balance analysis of primary metabolism in the diatom Phaeodactylum tricornutum. Plant J.: Cell Mol. Biol. 85, 161-176 (2016).

53. Mueller-Schuessele, S. J. \& Michaud, M. Plastid transient and stable interactions with other cell compartments. Methods Mol. Biol. 1829, 87-109 (2018).

54. Rast, A. et al. Biogenic regions of cyanobacterial thylakoids form contact sites with the plasma membrane. Nat. Plants 5, 436-446 (2019).

55. Collado, J. et al. Tricalbin-mediated contact sites control ER curvature to maintain plasma membrane integrity. Dev. Cell 51, 476-487.e477 (2019).

56. Hoffmann, P. C. et al. Tricalbins contribute to cellular lipid flux and form curved ER-PM contacts that are bridged by rod-shaped structures. Dev. Cell 51, 488-502. e488 (2019).

57. Scorrano, L. et al. Coming together to define membrane contact sites. Nat. Commun. 10, 1287 (2019).

58. Phillips, M. J. \& Voeltz, G. K. Structure and function of ER membrane contact sites with other organelles. Nat. Rev. Mol. cell Biol. 17, 69-82 (2016).

59. Prinz, W. A. Bridging the gap: membrane contact sites in signaling, metabolism, and organelle dynamics. J. Cell Biol. 205, 759-769 (2014).

60. Rowland, A. A. \& Voeltz, G. K. Endoplasmic reticulum-mitochondria contacts: function of the junction. Nat. Rev. Mol. cell Biol. 13, 607-615 (2012).

61. Merola, A. et al. Revision of Cyanidium caldarium. Three species of acidophilic algae. Plant Biosyst. 115, 189-195 (1981).

62. Mackinder, L. C. et al. A repeat protein links Rubisco to form the eukaryotic carbon-concentrating organelle. Proc. Natl Acad. Sci. 113, 5958-5963 (2016).

63. Meyer, M. T., McCormick, A. J. \& Griffiths, H. Will an algal CO2concentrating mechanism work in higher plants? Curr. Opin. plant Biol. 31, 181-188 (2016).

64. Badger, M. R. \& Price, G. D. The role of carbonic anhydrase in photosynthesis. Annu. Rev. Plant Physiol. Plant Mol. Biol. 45, 369-392 (1994).

65. Moroney, J. V. \& Mason, C. B. The role of the chloroplast in inorganic carbon acquisition by chlamydomonas-reinhardtii. Can. J. Bot. 69, 1017-1024 (1991).

66. Meyer, M. T., Whittaker, C. \& Griffiths, H. The algal pyrenoid: key unanswered questions. J. Exp. Bot. 68, 3739-3749 (2017).

67. Dauvillee, D. et al. Genetic dissection of floridean starch synthesis in the cytosol of the model dinoflagellate Crypthecodinium cohnii. Proc. Natl Acad. Sci. USA 106, 21126-21130 (2009).

68. Van Thinh, L., Griffiths, D. J. \& Winsor, H. Ultrastructure of symbiodinium microadriaticum (Dinophyceae) symbiotic with Zoanthus sp. (Zoanthidea). Phycologia 25, 178-184 (1986).

69. Gallagher, J., Wood, A. \& Alberte, R. Ecotypic differentiation in the marine diatom Skeletonema costatum: influence of light intensity on the photosynthetic apparatus. Mar. Biol. 82, 121-134 (1984).

70. Das, P., Lei, W., Aziz, S. S. \& Obbard, J. P. Enhanced algae growth in both phototrophic and mixotrophic culture under blue light. Bioresour. Technol. 102, 3883-3887 (2011).

71. Fang, X., Wei, C., Zhao-Ling, C. \& Fan, O. Effects of organic carbon sources on cell growth and eicosapentaenoic acid content of Nannochloropsis sp. $J$. Appl. Phycol. 16, 499-503 (2004).

72. Sforza, E., Cipriani, R., Morosinotto, T., Bertucco, A. \& Giacometti, G. M. Excess $\mathrm{CO}_{2}$ supply inhibits mixotrophic growth of Chlorella protothecoides and Nannochloropsis salina. Bioresour. Technol. 104, 523-529 (2012).

73. Marudhupandi, T., Sathishkumar, R. \& Kumar, T. T. A. Heterotrophic cultivation of Nannochloropsis salina for enhancing biomass and lipid production. Biotechnol. Rep. 10, 8-16 (2016).

74. Decelle, J. et al. Subcellular chemical imaging: new avenues in cell biology. Trends Cell Biol. 30, 173-188 (2020).

75. Sartori, A. et al. Correlative microscopy: bridging the gap between fluorescence light microscopy and cryo-electron tomography. J. Struct. Biol. 160, 135-145 (2007)
76. Stephens, D. J. \& Allan, V. J. Light microscopy techniques for live cell imaging. Science 300, 82-86 (2003).

77. Intergovernmental Panel on Climate, C. Climate Change 2014-Impacts, Adaptation and Vulnerability: Part B: Regional Aspects: Working Group II Contribution to the IPCC Fifth Assessment Report: Volume 2: Regional Aspects (Cambridge University Press, 2014).

78. Berges, J., Franklin, D. \& Harrison, P. Evolution of an artificial seawater medium: Improvements in enriched seawater, artificial water over the last two decades (Vol. 37: 1138-1145). J. Phycol. 40, 619 (2004).

79. Dolch, L.-J. et al. A palmitic acid elongase affects eicosapentaenoic acid and plastidial monogalactosyldiacylglycerol levels in Nannochloropsis. Plant Physiol. 173, 742-759 (2017).

80. Allen, M. B. Studies with Cyanidium caldarium, an anomalously pigmented chlorophyte. Arch. Mikrobiologie 32, 270-277 (1959).

81. Vaulot, D., Gall, F. L., Marie, D., Guillou, L. \& Partensky, F. The Roscoff Culture Collection (RCC): a collection dedicated to marine picoplankton. Nova Hedwig. 79, 49-70 (2004).

82. Butler, W. L. Energy distribution in the photochemical apparatus of photosynthesis. Annu. Rev. Plant Physiol. 29, 345-378 (1978).

83. Oliphant, T. E. Python for scientific computing. Comput. Sci. Eng. 9, 10-20 (2007).

84. Russo, F. An image enhancement technique combining sharpening and noise reduction. IEEE Trans. Instrum. Meas. 51, 824-828 (2002).

85. Kikinis, R., Pieper, S. D. \& Vosburgh, K. G. in Intraoperative Imaging and Image-guided Therapy (ed. Jolesz, F.) (Springer, 2014).

86. Cignoni, P. et al. MeshLab: an Open-Source Mesh Processing Tool. In Sixth Eurographics Italian Chapter Conference (eds Scarano, V., De Chiara, R. \& Erra, U.) 129-136 (Eurographics Digital Library, 2008).

87. Ranzuglia, G., Callieri, M., Dellepiane, M., Cignoni, P. \& Scopigno, R. MeshLab as a complete tool for the integration of photos and color with high resolution 3D geometry data. CAA 2012 Conference Proceedings (eds Graeme, E. et al.) 406-416 (Amsterdam University Press, 2012).

88. Ahrens, J., Geveci, B. \& Law, C. in The Visualization Handbook Vol. 717 (Data Science at Scale; Los Alamos National Laboratory, 2005).

89. Zhang, C., Chen, T. Efficient feature extraction for $2 \mathrm{D} / 3 \mathrm{D}$ objects in mesh representation. In Proceedings 2001 International Conference on Image Processing (Cat. No. 01CH37205)) (IEEE, 2001).

90. Helle, S. C. et al. Organization and function of membrane contact sites. Biochim. Biophys. Acta 1833, 2526-2541 (2013).

91. Decelle, J. et al. Phyto REF: a reference database of the plastidial 16S rRNA gene of photosynthetic eukaryotes with curated taxonomy. Mol. Ecol. Resour. 15, 1435-1445 (2015)

\section{Acknowledgements}

The authors thank the Roscoff Culture Collection that provided phytoplankton strains and Noan Le Bescot (Ternog Design) for help in the conception and realization of the figures of this article. This project received funding from the European Research Council: ERC Chloro-mito (grant no. 833184) to G.F., D.F., G.C. Research was also supported by a Défi X-Life grant from CNRS to J.D., funds from the CEA DRF impulsion FIB-Bio program to J.D., P.-H.J., B.G., C.M., D.F., G.S.; the European Union's Horizon 2020 research and innovation programme CORBEL under the grant agreement No 654248 to J.D., the LabEx GRAL (ANR-10-LABX-49-01), financed within the University Grenoble Alpes graduate school (Ecoles Universitaires de Recherche) CBH-EUR-GS (ANR-17-EURE-0003) to C.W., J.D., P.-H.J., B.G., C.M., F.C., G.C., G.S., D.F., G.F. and the ANR 'Momix' (Projet-ANR-17-CE05-0029) to G.C., G.F. This work used the platforms of the Grenoble Instruct-ERIC centre (ISBG; UMS 3518 CNRS-CEA-UGA-EMBL) within the Grenoble Partnership for Structural Biology (PSB), supported by FRISBI (ANR-10-INBS-05-02) and GRAL to B.G., C.M., G.S. The electron microscope facility is supported by the Auvergne-Rhône-Alpes Region, the Fondation Recherche Medicale (FRM), the funds FEDER and the GISInfrastructures en Biologie Santé et Agronomie (IBiSA) to B.G., C.M., G.S.; J.D. was supported by ATIP-Avenir program. C.U. is supported by a joint UGA-ETH Zurich PhD grant (to G.F. and S.C.Z.) in the framework of the "Investissements d'avenir" programme (ANR-15-IDEX-02)

\section{Author contributions}

C.U. designed the work, performed image treatment; made scripts and drafted the manuscript; J.D. designed the manuscript, prepared samples for FIB-SEM, interpreted data and drafted the manuscript; P.-H. J. conceived the work, performed FIB-SEM imaging and drafted the manuscript; S.F. characterized the physiological responses of LL and HL Phaeodactylum cells; B.G. performed sample preparation; J.B.K. performed image treatment and made scripts; D.D.B. characterized the physiological responses of phototrophic and mixotrophic Nannochloropsis cells; C.M. performed cryo fixation. G.A optimized growth of phototrophic and mixotrophic Nannochloropsis cells; F. Chevalier. optimized samples growth; C.S. characterized the physiological responses of LL and HL Phaeodactylum cells; N.L.S. performed FIB-SEM imaging; R.T. performed FIB-SEM 
imaging; F. Courtois. interpreted data; G.C. optimized samples growth and interpreted data; Y.S. performed FIB-SEM imaging and participated to manuscript drafting; G.S. designed the work and participated to manuscript drafting; S.C.Z. designed the work interpreted data and drafted the manuscript; D.F. designed the work, prepared samples for FIB-SEM, interpreted data and drafted the manuscript; G.F. designed the work; interpreted data and drafted the manuscript. All authors revised and approved the text.

\section{Competing interests}

The authors declare no competing interests.

\section{Additional information}

Supplementary information The online version contains supplementary material available at https://doi.org/10.1038/s41467-021-21314-0.

Correspondence and requests for materials should be addressed to J.D., D.F. or G.F.

Peer review information Nature Communications thanks Benjamin Engel, Koji Yamane, and the other, anonymous reviewer(s) for their contribution to the peer review of this work. Peer review reports are available.
Reprints and permission information is available at http://www.nature.com/reprints

Publisher's note Springer Nature remains neutral with regard to jurisdictional claims in published maps and institutional affiliations.

(c) (1)

Open Access This article is licensed under a Creative Commons Attribution 4.0 International License, which permits use, sharing, adaptation, distribution and reproduction in any medium or format, as long as you give appropriate credit to the original author(s) and the source, provide a link to the Creative Commons license, and indicate if changes were made. The images or other third party material in this article are included in the article's Creative Commons license, unless indicated otherwise in a credit line to the material. If material is not included in the article's Creative Commons license and your intended use is not permitted by statutory regulation or exceeds the permitted use, you will need to obtain permission directly from the copyright holder. To view a copy of this license, visit http://creativecommons.org/ licenses/by/4.0/.

(C) The Author(s) 2021 